\title{
Perfis editoriais e a construção de significados em impressos da educação física (1932-1960)
}

\author{
Juliana Martins Cassani ${ }^{1}$ \\ ORCID: 0000-0001-6332-7930 \\ Amarílio Ferreira Neto ${ }^{2}$ \\ ORCID: 0000-0002-3624-4352 \\ Wagner dos Santos ${ }^{2}$ \\ ORCID: 0000-0002-9216-7291
}

\section{Resumo}

A pesquisa possui como objetivo compreender as estratégias utilizadas pelos editores para constituir a imprensa periódica de ensino e de técnicas como meio de divulgação e convencimento do professorado, no que se refere à incorporação da educação física nos currículos escolares. Possui como fontes os editoriais de cinco revistas publicadas entre 1932 e 1960, caracterizadas por oferecer orientações didático-pedagógicas àqueles que atuariam com o ensino da educação física. 0 estudo utiliza como pressupostos teóricometodológicos os conceitos de lutas de representações, estratégias, táticas e a perspectiva de análise dos impressos. A interpretação das fontes acena para as disputas e as negociações entre os editores dos periódicos, especialmente entre grupos de articulistas civis e militares, o que favoreceu a publicação de orientações didático-pedagógicas fundamentadas em uma diversidade de métodos e exercícios. Em um cenário de consolidação de políticas educacionais, determinadas revistas se preocuparam em unificar o ensino da educação física, em um movimento que reconhecia as bases teóricas e as orientações didáticas já produzidas pela área. A análise evidencia que os periódicos cumpriram com a sua finalidade, qual seja, contribuir com o processo de escolarização da educação física, na medida em que houve o fortalecimento da atuação profissional, por meio da formação de professores em nível superior, no âmbito civil. Esse modo de organização da área permitiu a elaboração de um impresso cujas características levaram à transição de uma imprensa dedicada ao ensino e à técnica para aquela dedicada à pesquisa, oferecendo as bases para o periodismo científico da educação física.

\section{Palavras chave}

Historiografia - Imprensa periódica - Periódicos educacionais - Editores - Educação física.

1- Universidade Federal do Tocantins, Miracema, Tocantins, Brasil. Contato: juliana.cassani@mail.uft.edu.br

2- Universidade Federal do Espírito Santo, Vitória, Espírito Santo, Brasil. Contatos: amariliovix@gmail.com; wagnercefd@gmail.com 


\section{Editorial profiles and the construction of meanings in physical education printed materials (1932-1960)}

\section{Abstract}

The objective of this study is to comprehend the strategies utilized by publishers in order to turn the periodical press devoted to teaching and techniques as a means to disseminate and persuade teachers concerning the introduction of physical education in the school curricula. The sources are the editorials from five magazines published between 1932 and 1960, whose common characteristic was to provide those working on teaching physical education with didactic-pedagogical guidance. Theoretical-methodological assumptions of the study are the concepts of struggles for representations, strategies, tactics, and the perspective of analysis of the printed materials. Interpreting sources dangles towards the disputes and negotiations among the publishers of periodicals, especially among groups of civil and military writers, as it benefitted the publication of didactic-pedagogical guidance based on a diversity of methods and exercises. In an environment where educational policies were consolidated, certain magazines were concerned about unifying the teaching of physical education, in a movement that acknowledged the theoretical bases and the pedagogical orientation already established in the area. Analysis reveals that periodicals fulfilled their purpose, namely, contribute to make physical education a school subject as there the professional work is this area had grown stronger through teacher training in higher education in the civil domain. This way of organizing the area allowed to devise a printout whose characteristics led to the transition from a press dedicated to teaching and technique to a press dedicated to research, providing the bases for scientific periodicals covering physical education.

\section{Keywords}

Historiography - Periodical press - Educational periodicals - Publishers - Physical education.

\section{Introdução}

Foi em um cenário de embates e negociações que, em 1931, a inserção da educação física (EF) foi regulamentada nas instituições de ensino secundárias, em caráter nacional. À época, a Reforma Francisco Campos (BRASIL, 1931) serviu como estratégia do Governo Provisório de Getúlio Vargas (1930-1934) para desenvolver uma "política modernizadora" do ensino secundário, centralizada no recém-criado Ministério da Educação e Saúde Pública (MES). Sob a sua responsabilidade, decidiam-se: as matérias presentes nas séries dos cursos fundamental e complementar; a homogeneização do ensino e da avaliação; e a obrigatoriedade dos exercícios da EF, em todo o ano letivo e para todas as classes. 
Por não compor as matérias do curso fundamental ou as disciplinas obrigatórias do curso complementar, a EF foi inserida na Reforma (BRASIL, 1931) sem que, em termos legais, fossem apresentadas orientações para sistematizá-la nos currículos. No entanto, de modo paradoxal, o MES determinou que todos os exercícios realizados nas escolas fossem fiscalizados por inspetores, o que implicaria acompanhamento dos programas escolares, das práticas de ensino e da seriação da EF.

Nesse contexto de implementação de políticas públicas educacionais, as editoras também foram impulsionadas a produzir "[...] livros, inúmeras revistas e boletins especializados" (BASTOS, 1997, p. 85), preocupados especificamente com os problemas relacionados com a Educação. ${ }^{3}$ Em um período de intensos debates na área, parece-nos que o estímulo a essas publicações também alcançou os articulistas dedicados à causa da EF, pois, diante da ausência de critérios para a sua organicidade, observada na Reforma Francisco Campos (BRASIL, 1931), a circulação de impressos destinados à orientação da prática pedagógica dos profissionais de EF, também contribuiria para a sua sistematização e consolidação nos currículos escolares.

Uma leitura desses materiais, denominados "imprensa periódica de ensino e de técnicas” (FERREIRA NETO, 2005a), evidencia aproximações com a imprensa periódica direcionada para a área mais ampla da Educação. Pela proficuidade com que a historiografia educacional tem assumido esses impressos, ou seja, como fontes e objetos de estudos, temos acompanhado o processo com o qual eles têm oferecido as bases para o fortalecimento de uma trajetória de pesquisas sobre o tema.

Dentre elas, Catani (1994) e Catani e Souza (1999) afırmam que as revistas especializadas em educação configuram fontes de análise privilegiada e em núcleos informativos, em que é possivel apreender os modos de funcionamento do campo educacional, as informações sobre o trabalho pedagógico, o aperfeiçoamento das práticas docentes, o ensino específico das disciplinas, a organização dos sistemas, as reivindicações da categoria do magistério, a participação dos agentes produtores dos periódicos na organização dos sistemas de ensino e na elaboração dos discursos que visam instaurar as práticas exemplares. Esse olhar permite ao historiador explicitar as predominâncias, as recorrências temáticas, informações sobre os autores e as prescrições ou recomendações sobre formas ideais de realizar o trabalho docente.

Por sua vez, Carvalho (2001) dedica-se à análise pela materialidade dos impressos destinados ao professorado, tomando-os como fontes e como objetos. Ao focalizar as estratégias de difusão e apropriação dos saberes pedagógicos inscritos nesses documentos, a autora os assume como dispositivos que normalizam o conhecimento dirigido ao ensino e às práticas que visam às aprendizagens dos alunos. Essa ênfase permite ao pesquisador analisar a multiplicidade de dispositivos materiais, considerando-os objetos culturais com finalidades específicas. Ainda, para a autora, os impressos destinados ao professorado estariam alicerçados: na moderna pedagogia como "arte de ensinar", fundamentando a elaboração de impressos semelhantes a "caixas de utensílios”, em que eram prescritas

3- Esse cenário foi gerado, sobretudo, pela divulgação do Manifesto dos Pioneiros da Educação Nova no ano de 1932. 0 documento foi reconhecido como síntese de todas as ideias e iniciativas "renovadoras" no campo da educação, apresentando-se como condição ao progresso educacional, em um movimento de defesa pela escola pública, obrigatória, gratuita e leiga (XAVIER, 2002). 
"coisas para usar", modelos para serem imitados pelos professores, roteiros de lições e práticas exemplares; e na Pedagogia da Escola Nova, oferecendo fundamentos teóricos científicos e filosóficos para a prática docente, por meio de "coleções pedagógicas".

Em diálogo com essas pesquisas, compreendemos que a imprensa periódica de ensino e de técnicas da EF, segundo Ferreira Neto (2005a), possui finalidades semelhantes aos impressos educacionais analisados pela história da educação. Publicados a partir de 1930, em formato revista (tamanhos livro e A4), esses periódicos lutavam pela escolarização, formação profissional e por legislações específicas para a EF. Os articulistas também faziam circular metodologias para o ensino dos exercícios e dos métodos ginásticos, bem como publicavam referenciais teóricos que ofereceriam suporte para a prática pedagógica.

Esses achados evidenciam as preocupações dos impressos com o ensino da EF, aproximando a natureza dessas fontes àquelas analisadas por Catani (1994), Catani e Souza (1999) e Carvalho (2001). Concomitantemente a essas semelhanças, Ferreira Neto (2005a) também captou matérias específicas sobre os esportes, que buscavam aprofundar os conhecimentos dos leitores em relação às suas instalações, materiais, detalhamentos técnicos e noticiários sobre organizações esportivas.

Com base nessas características e em diálogo com Faria e Pericão (2008), o autor passou a denominá-la imprensa periódica de ensino e de técnicas, pois, uma publicação técnica se refere àquela que trata exclusivamente de determinados temas, em nosso caso, dos esportes (FERREIRA NETO, 2005a). Essas especificidades nos permitem inferir que no interior dos impressos de ensino da EF também se desenvolveu um tipo de imprensa técnica, fazendo com que imprensas de diferentes naturezas dialogassem nas páginas das revistas destinadas ao professorado.

Conforme explicita Cassani (2018), a publicação da imprensa técnica dentro da imprensa de ensino evidencia que, para a inserção e consolidação da EF no projeto de escolarização, também era preciso divulgar as orientações em relação a: o que, como, quando, para quem e onde ensinar e aprender os esportes. Para atender ao fim mais amplo da EF, seja para o trabalho na escola, seja em outros espaços, não era possível desassociar as duas formas de imprensa que se retroalimentavam mutuamente.

Diante do exposto, este artigo ${ }^{4}$ possui como objetivo compreender as estratégias utilizadas pelos editores para constituir a imprensa periódica de ensino e de técnicas como meio de divulgação e convencimento do professorado, no que se refere à incorporação da EF nos currículos escolares.

\section{Fontes e procedimentos}

Tomamos como referência os estudos de Chartier (1990) sobre as lutas de representações, que constituem práticas dispostas em um campo de concorrência, de competições e de disputas por poder. Por meio delas, grupos de intelectuais constroem e dão a ler um mundo social, elaborando matrizes de "discursos" sobre os seus interesses "objetivamente confrontados”. Essas lutas de representações são produzidas em meio a

4- 0 artigo é desdobramento de projeto de pesquisa financiado pela Capes (Doutorado), Fapes (Edital Universal 06/2014, Processo 67.6438.25) e CNPq (Edital Universal 28/2018, Processo 43.5195/2018-2). 
múltiplas relações intrínsecas ao texto impresso, que envolvem estratégias de circulação de saberes, escolhas e condutas de editores. Para Chartier (1990, p. 17), elas "[...] têm tanta importância quanto as lutas econômicas para a compreensão dos mecanismos pelos quais [os grupos impõem], ou [tentam] impor, sua concepção de mundo social, seus valores e seu domínio".

Mediante as intencionalidades dos grupos de editores em circulação nos impressos, assumimos os conceitos de estratégias de conservação e táticas de subversão (CERTEAU, 2002), imbricadas aos projetos editoriais dos periódicos e aos lugares ocupados por aqueles que as produziram. De acordo com o autor, as táticas de subversão são geradas pela ausência de lugares próprios, como um último recurso daqueles que, com mobilidade, se submetem aos que detêm o poder. Sua finalidade é influenciar o espaço, criando novas estratégias. Estas, por sua vez, são manipulações das relações de força que sustentam e conquistam lugares de produção. Elas se tornam possíveis quando um sujeito de querer e poder circunscreve um lugar como algo próprio, em uma exterioridade a alvos ou ameaças.

Também nos baseamos nos estudos de Chartier (2002) sobre a análise dos impressos, compreendendo-os como fontes, objetos culturais e produtos de relações entre autores e editores, em que saberes, modelos e formas de pensar são colocados à leitura. Ao analisamos os múltiplos dispositivos produzidos estrategicamente pelos articulistas, a fim de "induzir" à leitura do impresso, compreendemos que "[...] não há texto fora do suporte que o dá a ler, e sublinhar o fato de que não existe a compreensão de um texto, que não dependa das formas através das quais ele atinge o leitor" (CHARTIER, 2002, p. 127).

A justificativa para a periodização das fontes (1932-1960) apresenta motivos internos e externos ao objeto. Internamente, o ano de 1932 refere-se à publicação dos primeiros números das revistas que possuem o perfil editorial discutido por Ferreira Neto (2005a), dedicado a orientar a prática e a formação dos profissionais que atuariam nas instituições escolares. São elas: a Revista de Educação Física (REF) e a Revista Educação Physica (REPHy). Os motivos externos estão associados ao ano de término desse tipo de impresso, 1960, pois, cumprindo os seus propósitos, acabou por fenecer, “[...] faltando encontrar o seu lugar no século XXI" (FERREIRA NETO, 2005a, p. 776).

Com a inserção da EF na escola e a regulamentação da formação de professores em nivel superior, os editores e articulistas entenderam que caberia aos cursos de formação ensinar aos futuros professores sobre a organização e o planejamento de suas práticas pedagógicas. Para Ferreira Neto (2005a, 2005b), como o espaço legal da EF fora garantido pelas contribuições dos impressos de ensino e de técnicas, paulatinamente, pós 1960, o periodismo passou a figurar como publicações científıcas, fruto da necessidade de o campo acadêmico orientar a área por meio de pesquisas vinculadas à graduação, à pósgraduação, às sociedades científicas e às associações de categoria profissional.

Fundamentados nessas especificidades, assumimos como fontes os editoriais dos seguintes impressos: Revista de Educação Física - REF (1932-1960), Revista Educação Physica - REPHy (1932-1945), Boletim de Educação Física - BEF (1941-1958), Revista Brasileira de Educação Física - RBEF (1944-1952) e Arquivos da Escola Nacional de Educação Física - AENEFDs (1945-1966). Para selecioná-los, consideramos o conceito de Faria e Pericão (2008) sobre editoriais, entendidos como artigos de jornais ou revistas que 
expressam o pensamento e a orientação dos seus dirigentes em relação aos assuntos de sua época, normalmente publicados na primeira página. Eles "[...] [estão] sempre presentes e [...] [constituem] a peça forte, quando [exprimem] frontalmente uma posição própria" (FARIA; PERICÃo, 2008, p. 272).

Denominados por Chartier (2014) de paratextos, os editoriais se caracterizam por introduzir assuntos e materializar uma identidade aos periódicos, tornada perceptível por meio dos sinais particulares utilizados pelos editores, como o uso de um tipo de fonte, símbolos e normas da língua vernácula. Por meio deles, captamos as considerações dos editores sobre a escolarização da $\mathrm{EF}$, bem como as disputas que ocorriam entre as diferentes revistas, tendo como base o seu projeto editorial. Eles estão assim distribuídos:

Tabela 1 - Distribuição dos editoriais por periódico

\begin{tabular}{ccc} 
PERIÓDICOS & TOTAL DE EDITORIAIS \\
\hline REF & $\vdots$ & 76 \\
\hline REPHy & $\vdots$ & 71 \\
\hline BEF & $\vdots$ & 16 \\
\hline RBEF & $\vdots$ & 60 \\
\hline AENEFD & $\vdots$ & 13 \\
\hline TOTAL & 236 \\
\hline
\end{tabular}

Fonte: dados da pesquisa.

Elaboramos um banco de dados no Microsoft Excel para cada uma das revistas, contendo: ano da revista, número, autores dos editoriais e títulos. Posteriormente, criamos um banco de dados para cada periódico no software IBM ${ }^{\circledR}$ SPSS $^{\circledR}$ Statistics - Version 22, atribuindo variáveis para essas informações. 0 uso desse programa, como instrumento para organização das fontes, possibilitou uma visão ampliada do objeto da pesquisa, ajudou na localização e manuseio do corpus documental, assim como favoreceu a compreensão da forma e conteúdo das fontes.

\section{Tensões e diálogos entre civis e militares}

Dentre os periódicos analisados, a REF foi criada em 1932, chancelada pela Escola de EF do Exército (EsEFEX), no Rio de Janeiro (RJ). 0 periódico sofreu interrupções entre 1943 e 1947, pela participação das Forças Armadas na Segunda Guerra Mundial, mantendo-se em circulação até os dias de hoje. Em seu primeiro editorial, o primeirotenente João Ribeiro Pinheiro, como seu editor-chefe, explicitou o papel da Instituição em esculpir a raça e a nacionalidade dos brasileiros, conforme Figura 1: 
Figura 1 - Editorial da REF

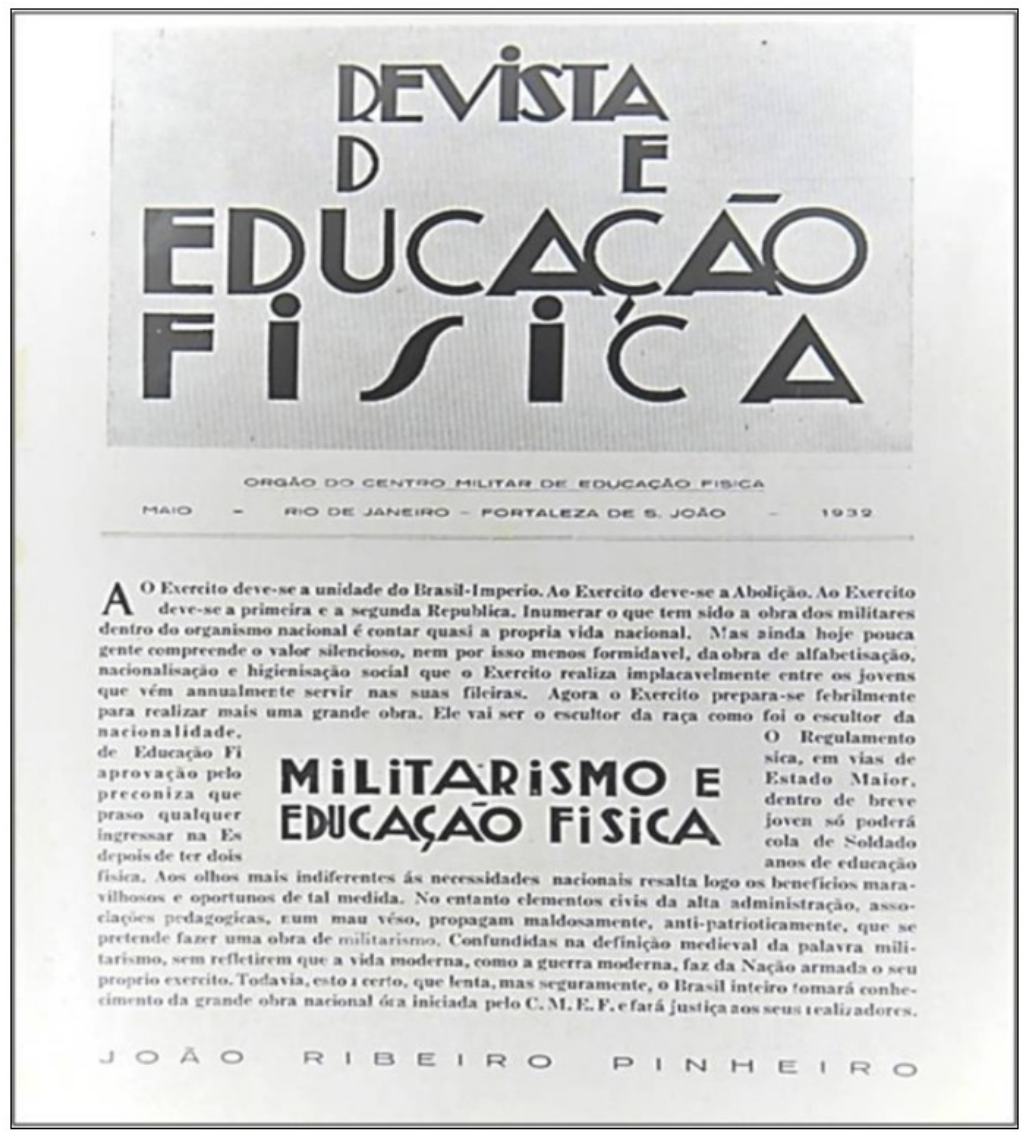

Fonte: dados da pesquisa

0 título do editorial, "Militarismo e educação física", centralizado no corpo da matéria e escrito com as mesmas fontes do nome da revista, demonstrava unidade do layout e a importância do debate à época, por isso a sua presença no número que iniciou o ciclo de vida da REF. 0 editor "[...] [enumerou] o que tem sido a obra dos militares dentro do organismo nacional” (PINHEIRO, 1932a, s. p.), com o intuito de enfatizar as ações do Exército em prol do Brasil. Para ele, relembrar os feitos da instituição seria semelhante a "contar a própria vida nacional”, pois movimentos políticos históricos, como a unidade do Brasil-Império, a Abolição, a instituição da Primeira e Segunda República, deviam-se ao Exército, ou seja, sua participação foi uma condição, sem a qual esses marcos não teriam acontecido (PINHEIRO, 1932a).

0 editorial foi oportuno para Pinheiro (1932a) esclarecer que as iniciativas da instituição em alfabetizar, nacionalizar e "higienizar" socialmente jovens e crianças, mesmo "silenciosas”, trariam “colaborações profícuas e indispensáveis” à Nação, tal como ocorrera no âmbito político. 0 articulista referia-se às recentes tensões promovidas no campo 
educacional, por “[...] elementos civis da alta administração, associações pedagógicas, [...] [que] [propagavam] maldosamente, anti-patrioticamente, que se [pretendia] fazer uma obra de militarismo" na educação (PINHEIRO, 1932a, s. p., grifo do autor).

0 seu questionamento foi direcionado aos diretores dos Congressos organizados pela Associação Brasileira de Educação (ABE) que, até aquele momento, não haviam convidado o Exército para participar dos eventos anteriores, em uma "[...] prova de ignorância à grande obra que o Exército [realizava] silenciosamente, através das escolas regimentais" (PINHEIRO, 1932b, s. p.).

0 editorial, como um espaço de visibilidade ao pensamento da instituição, fazia repercutir as disputas e as negociações sobre determinado tema à sociedade, tornando pública a insatisfação de Pinheiro (1932a, 1932b) em relação às indagações da ABE sobre a futura atuação do Exército nas escolas. A ausência do convite da Associação para que os militares participassem dos Congressos, silenciando-os, comprometia, para o editor, as contribuições do Exército para a escolarização da EF, desconsiderando, inclusive, outras ações da instituição que fizeram o país "avançar" historicamente.

0 descontentamento de civis em relação ao Exército estaria associado a uma possível aplicação do "Réglement géneral de éducation physique" (Méthode française), Regulamento geral de EF (Método françês) ${ }^{5}$ nas escolas brasileiras, por intermédio dos instrutores e monitores formados pela EsEFEX a partir de 1933. Como cenário dessas tensões, estava a "(in)compreensão" da sociedade civil sobre a concepção educacional da Doutrina do Exército, baseada "[...] na disciplina como desdobramento das forças físicas, morais, intelectuais e psicológicas" (FERREIRA NETO, 1999, p. 47) - esta seria a "pretensa obra de militarismo" a qual Pinheiro (1932a) se referia, em uma crítica ao pensamento "confuso" de intelectuais civis.

Em meio às tensões entre civis e militares, os editoriais da REF anunciavam a necessidade de vulgarização da "[...] grande obra nacional óra iniciada pela [EsEFEX], [fazendo] justiça aos seus [idealizadores]" (PINHEIRO, 1932a, s. p.). 0 editor referia-se aos "benefícios" do Método Francês, cuja aplicação obteria "formidáveis repercussões sobre o lado moral e intelectual, [...] a força, a dextresa, a resistencia, a velocidade, a harmonia de formas, a coragem, a audacia, o sangue frio, a tenacidade [...]” (MOLINA, 1932, s. p.) dos jovens brasileiros.

Nesse caso, é preciso considerar que a obrigatoriedade da EF no ensino secundário se fazia "oportuna" para o Exército, haja vista a exigência de praticá-la nessas instituições, ao jovem interessado em ingressar na Escola de Soldado. Como os resultados gerados pela instrução pré-militar, realizada nas escolas civis, não eram aqueles esperados pela caserna, a aprovação da Reforma contribuiria para que o Exército recebesse o recruta desejado, sobretudo porque ele seria ensinado, no período de dois anos, por instrutores e monitores formados pelo Método Francês, na EsEFEX (FERREIRA NETO, 1999).

Desse modo, a REF servia para divulgar as “colaborações” do Exército ao ensino da EF nas escolas secundárias, forjando-a como porta-voz de articulistas que viam no

5- 0 método foi criado pela Escola Normal de Ginástica e de Esgrima de Joinville-Le-Pont (França), na década de 1920. Ele foi 0 orientador da EF na EsEFEX, servindo de base para a formação de profissionais que atuariam com a EF nas instituições de ensino civis (CAVALCANTI, 1932). 
método francês o meio pelo qual seria idealizado um projeto oficial de EF no Brasil. 0 impresso foi utilizado como estratégia de convencimento em relação ao papel exercido pelo Exército no processo de inserção e consolidação da EF nos currículos escolares, a fim de construir uma "grande pátria brasileira". Como recurso de persuasão do seu público leitor, fez circular a opinião de intelectuais que, por sua importância na sociedade, garantiam confiabilidade, repercussão e adesão às investidas da instituição em lançar os fundamentos para a sistematização da EF, por meio do periódico.

Houve, nesse caso, a apropriação de estratégias editoriais semelhantes àquelas em circulação no campo da educação, como a publicação de matérias assinadas por pessoas formadoras de opinião, figuras públicas eminentes, cuja voz influenciaria a implementação de mudanças nas políticas educacionais, ganhando a adesão da sociedade e o apoio dos professores. Práticas como essas já estavam presentes no Manifesto dos Pioneiros da Educação Nova (1932) que, para Xavier (2002), teve o impacto almejado no cenário educacional, pela estratégia de Fernando de Azevedo em convidar intelectuais que contribuíssem com a divulgação do manifesto, especialmente jornalistas.

$\mathrm{Na}$ REF, foi Assis Chateaubriand (1934) quem assumiu o papel de mostrar para o público a importância da EsEFEX e do impresso para a escolarização da EF. Seu editorial remetia o leitor à necessidade encontrada pela Escola em desenvolver-se "em toda a amplitude pedida pelos seus fins transcendentes” (p. 1), sendo necessário, para isso, receber no ginásio "elementos civis", crianças e rapazes, para educá-los no amor dos jogos ao ar livre. Chateaubriand (1934, p. 1) ainda afırmou que "essa intercomunicação da caserna com a sociedade civil era uma das indispensáveis condições para que o Exército se transformasse como deve, num agente de aperfeiçoamento".

Ao fazer uso do editorial para sinalizar a necessidade de diálogo entre civis e militares, o jornalista reafırmou a responsabilidade do Exército na formação "da alma e do corpo" da juventude brasileira. No entanto, essas ações só seriam possíveis pelo "diálogo" requerido pelo articulista, oferecendo-nos pistas (GINZBURG, 1989) das estratégias do Exército em aproximar os diferentes grupos de intelectuais (civis e militares), desde que as suas prerrogativas fossem as orientadoras do processo de escolarização de EF. ${ }^{6}$

Nesse espaço de embates, iniciativas em veicular orientações para as práticas da EF materializavam-se também em periódicos de natureza civil, como a REPHy. Publicada pela Cia. Brasil Editora S. A., no RJ, o periódico circulou até o ano de 1945. 0 seu projeto editorial consistia em propagar princípios científicos para a escolarização e formação profissional em EF, além de divulgar os esportes, seus fins morais e sociais. 0 objetivo da revista era apoiar a causa da EF, tornando-se uma base orientadora para todo o Brasil e também para outros países. A Figura 2 apresenta os eixos que fundamentavam a publicação do impresso:

6- Para Ferreira Neto (1999), os eixos doutrinários e pedagógicos do Exército que orientavam o ensino da EF na caserna eram diferentes daqueles realizados na escola, embora essa diferenciação nem sempre seja reconhecida pela produção científica da EF. 
Figura 2 - Eixos orientadores da Revista Technica

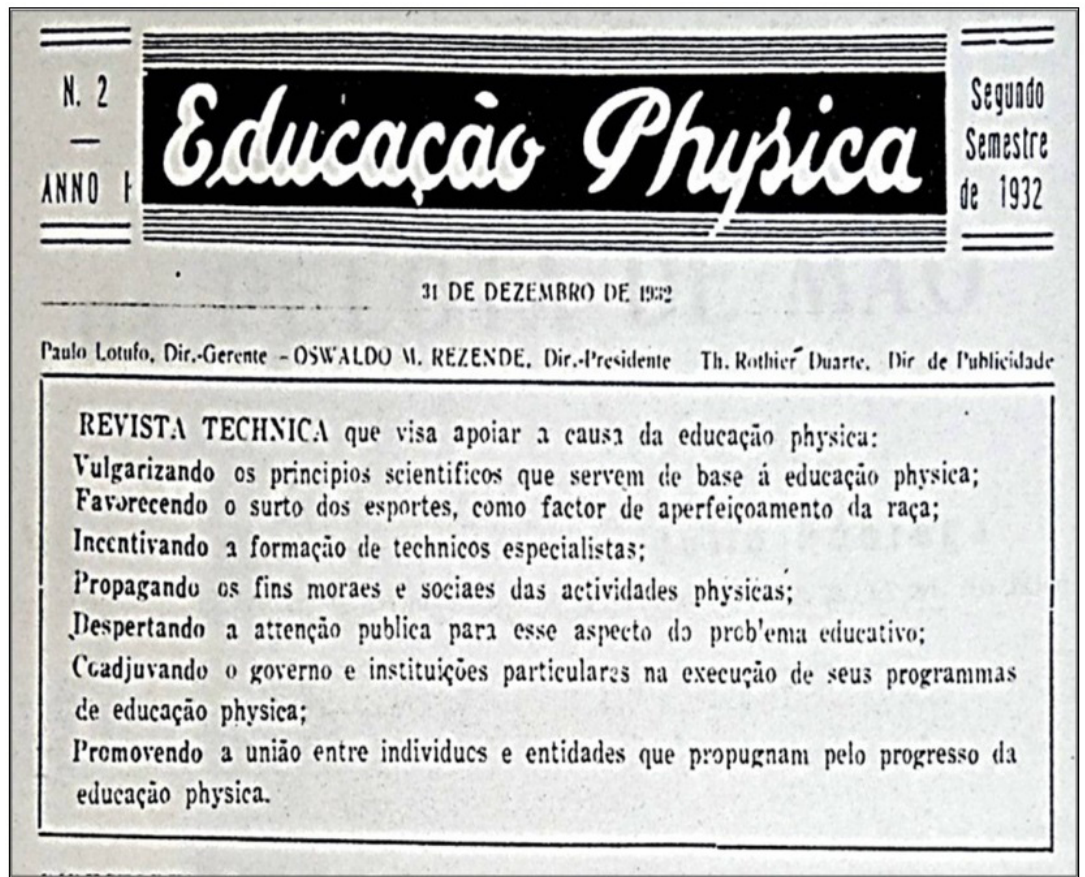

Fonte: Revista Technica (1932, s. p.).

Em um cenário no qual havia um periódico que se autointitulava porta-voz oficial do processo de escolarização da EF, era preciso convencer o público sobre a importância da REPHy. Por isso, a estratégia dos editores em publicar esses dispositivos de leitura, em todo o seu ciclo de vida, buscava constituí-la como periódico de referência entre os professores, diferenciando-a dos eixos orientadores da REF.

Com base em Certeau (2002), é possível inferir que as táticas dos editores em "coadjuvar", ou seja, auxiliar o Governo e as instituições particulares na execução dos programas da EF (REVISTA TECHNICA, 1932, s. p.), tinha a finalidade de obter a "aceitação" de seus leitores. Era preciso "reconhecer" aqueles que "oficialmente" contribuiriam com a escolarização da EF, a fim de apresentar outras possibilidades de orientação didáticopedagógica para os professores, garantindo-lhes um conteúdo abrangente. ${ }^{7}$

Outra prática dos editores ${ }^{8}$ era conferir à REPHy a expressão de um ideal generalizado, um veículo em que um grupo de "sonhadores" poderia ver "[...] implantada no espírito de nossa gente uma compreensão mais ampla, mais viva, mais real da verdadeira finalidade da educação" (EDITORIAL, 1934, p. 11, grifo nosso). A escrita do editor, nesse caso,

7- Além das prescrições fundamentadas nos discursos oficiais (Método Francês), circulavam também aquelas referentes aos Métodos Sueco e Alemão.

8- Diante da ausência de identificação de autoria, nos editoriais da REPHy, atribuímos essas matérias a Oswaldo Murgel Rezende (ex-professor de EF da Associação Cristã de Moços, do RJ). Ele foi diretor presidente do impresso em todo o seu ciclo de vida. 
enaltecia a revista pelo uso recorrente do advérbio de intensidade "mais", constituindo-se em um dispositivo de leitura para convencer os leitores sobre o papel a ser exercido pela própria REPHy, isto é, ela seria o periódico que "melhor" orientaria a prática e a formação profissional daqueles que atuariam com o ensino da EF na escola.

A valorização do periódico também viria pela estratégia de anunciar o apoio de profissionais de diferentes segmentos, como diretores de colégios e de associações esportivas, educadores, jornalistas, cultores do esporte e demais indivíduos, que apoiariam e aplaudiriam "ardorosamente" a revista. Os editores sinalizavam que a aceitação do impresso junto à sociedade civil já era uma "realidade" entre aqueles comprometidos com a EF (EDITORIAL, 1934), ou seja, naquele cenário de concorrências, a REPHy congregava os civis, por quem os editores da REF ainda buscavam dialogar.

As táticas dos editores também consistiam em anunciar a REPHy como colaboradora do "são entusiasmo" vivido no país, em relação à EF. Aquele "scenario de rejuvenescimento", fruto das iniciativas do impresso, construía um ambiente de "[...] simpatia ao trabalho racional da cultura intelectual e física, [constituindo-se] [...] parte daquillo que [idealizavam] e para o que [trabalhavam]" (EDITORIAL, 1936, p. 11).

Também sinalizamos dispositivos de leitura que atribuíam à REPHy a responsabilidade de propagar o ensino da EF, oferecendo aos professores "[...] mais e mais [...] ensinamentos technicos que [deviam] existir nos sports e athletismo brasileiros" (EDITORIAL, 1936, p. 11, grifo nosso). Assim, diante de uma instituição oficialmente reconhecida como aquela que promoveria a EF, os editores da REPHy colocavam-na como um suporte material que contribuiria de modo "mais eficaz" com esse processo, oferecendo prescrições didáticopedagógicas sobre esportes e atletismo - mesmo que publicações como estas também circulassem na REF.

Seja sob a chancela dos militares, seja sob a de civis, os editoriais da REF e da REPHy se aproximavam pela estratégia de reconhecer a sociedade civil como colaboradora dos impressos, com o objetivo de consolidar a EF no País. Na REF, persuadia-se o público leitor em relação às "contribuições" do Exército à nação brasileira, especificamente pelo acolhimento "caloroso" de elementos civis em suas tropas, a fim de formar monitores e instrutores que cumpririam a "missão" de propagar os princípios científicos de uma raça forte e saudável, nas escolas. Na REPHy, a estratégia consistia em convencer os diferentes segmentos da sociedade civil de que a revista já contava com a aceitação de todos aqueles que defendiam a causa da EF, fortalecendo o seu projeto editorial.

Para se constituírem como autoridade no mercado editorial e se moverem pelos lugares institucionalizados (CERTEAU, 2002), os editores da REPHy assumiam taticamente os princípios em voga no Exército, compartilhando com a instituição a "missão" de construir uma raça forte e saudável. Os editoriais da REPHy criavam identidades ao impresso, na medida que estabeleciam semelhanças com a REF (comprometendo-se a formar um "ideal de brasileiro sadio"), mas também o faziam pela diferenciação, ao anunciarem as teorias que fundamentavam o seu perfil editorial, isto é, pela concepção de formação humana integral helênica, ${ }^{9}$ em que "[...] a cultura physica [estava] de par com o aperfeiçoamento do caracter e o enriquecimento do espirito” (EDITORIAL, 1938, p. 9).

\footnotetext{
9- Perspectiva essa que ganha força, no Brasil, pelos estudos de Fernando de Azevedo.
} 
As disputas pelo lugar de autoridade entre civis e militares, especificamente no que se refere ao reconhecimento dos impressos como orientadores da prática pedagógica, antes de ser uma especificidade da EF, expressam um cenário de embates no campo mais macro da política e da Educação, conforme Vidal (2013). Ao analisar o "Manifesto dos Pioneiros da Educação Nova" (1932), a autora discute as tensões decorrentes das políticas do Governo Provisório (1930-1934), direcionadas a modernizar o sistema educativo brasileiro, oferecendo-nos pistas dos embates que estavam em circulação.

Para Vidal (2013), a publicação do "Manifesto" foi motivada pelo interesse de um grupo de intelectuais em controlar o MES, buscando constituir os princípios orientadores da educação no país, dentre eles, atribuir responsabilidade ao Estado pela disseminação da escola, garantindo-lhe laicidade, gratuidade e obrigatoriedade. Os questionamentos desses intelectuais à "Reforma Francisco Campos" (1931) mostravam que a política centralizadora do Estado, homogeneizando matérias, disciplinas, métodos e práticas avaliativas, era considerada um "centralismo estéril".

As "fraturas" entre o responsável pela Reforma, no caso, Francisco Campos, e aqueles que também ocupavam lugares oficiais do Governo, como Fernando de Azevedo, Anísio Teixeira e Lourenço Filho, anunciaram, para Vidal (2013), que os embates no campo educacional estavam intrinsecamente ligados a tensões de natureza política. A descentralização do sistema educacional defendida por Azevedo, Teixeira e Lourenço Filho foi decorrente das disputas politicas realizadas entre as elites estaduais, em especial paulistas, que viam na centralização da educação uma ameaça aos anseios pelo federalismo e autonomia do Estado de São Paulo (VIDAL, 2013). Situação essa, contrária aos princípios do Governo Vargas, que defendia a centralização das práticas educacionais e políticas.

Este panorama de tensões em relação às políticas educacionais, também impactou intelectuais civis e militares que, no âmbito da EF, buscavam se constituir como referências no Brasil. 0 interesse em torná-la obrigatória nos currículos escolares era compartilhado, mas seria necessária a adoção de um método? Era preciso unificar o ensino da EF no país, coadunando com as propostas educacionais centralizadoras do Governo?

Se os editores da REF viam o Exército como o responsável por cumprir esse papel, por outro lado, os editoriais da REPHy indagavam a ideia de que havia uma única instituição orientadora da EF no país. Ao constituírem matrizes discursivas (CHARTIER, 1990) para os impressos, os editoriais evidenciavam as suas contribuições no processo de escolarização da EF: na REF, os editoriais eram porta-vozes do "compromisso" dos militares com a uniformização da EF, fundamentada no Método Francês; já na REPHy, os editores assumiam-na como a materialização dos anseios de uma coletividade (EDITORIAL, 1934), oferecendo outras possibilidades de ensino para os professores.

\section{Da consolidação à transição de projetos editoriais}

0 ano de 1937 foi profícuo para compreendermos o modo como a política e a educação brasileiras se imbricam. Getúlio Vargas instaurou o Estado Novo (1937-1945), reconheceu oficialmente o uso do método francês como orientador da EF nas escolas e promulgou a Constituição, que tornou obrigatório o ensino da EF nas instituições primárias, normais e secundárias. Naquele mesmo ano foi criada a Divisão de Educação 
Física (DEF), órgão do Ministério de Educação e Saúde (MES), responsável por administrar todas as atividades da área.

Dirigida pelo major João Barbosa Leite, a DEF publicou o primeiro número do BEF em 1941. Em 1946, as atividades do impresso foram paralisadas, retornando entre 1955 e 1966. As Figuras 3 e 4 apresentam a Capa e o seu primeiro editorial:

Figura 3 - Capa do BEF

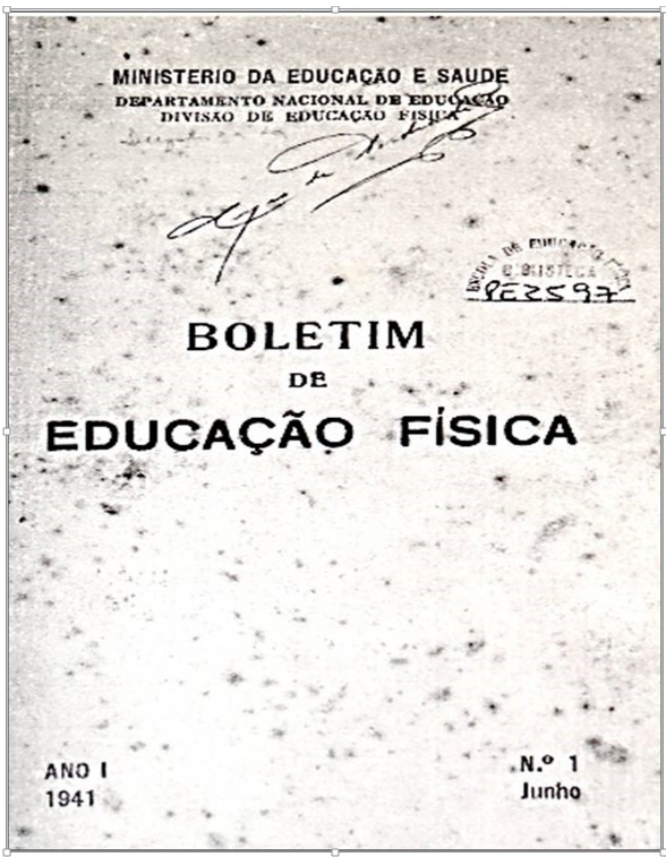

Fonte: Capa (1941).
Figura 4 - Editorial do BEF

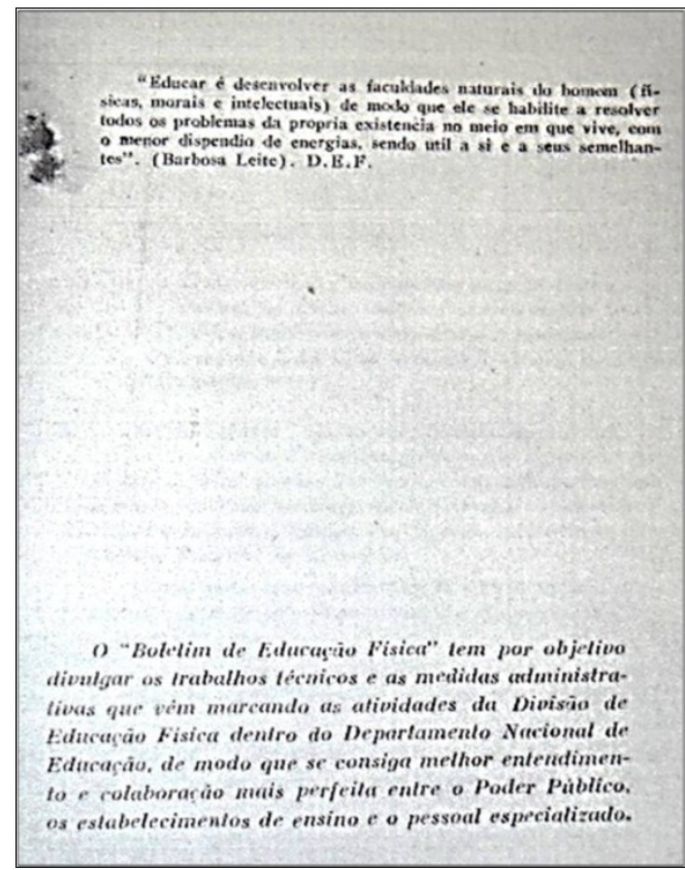

Fonte: Leite (1941a).

Conforme a Figura 4, os editoriais do BEF caracterizavam-se por apresentar: citações a autores, finalidades e assuntos abordados pelo impresso. Nesse periódico, a capa e o artigo de abertura são pistas para os dispositivos de leitura mobilizados para compor o seu perfil editorial: a impressão era feita com recursos visuais escassos, com poucos desenhos e fotografias, com letras padronizadas em todo o ciclo de vida e monocromáticas.

Sob esse aspecto, o perfil editorial da REF e da REPHy eram semelhantes, pois, a fim de orientar a prática e a formação daqueles que ensinariam a EF, faziam uso de fotografias, desenhos e ilustrações antropomórficas, oferecendo modelos para que os leitores se apropriassem corporalmente dos exercícios e, assim, terem condições de ensiná-los (RETZ et al., 2019). Conforme Cassani (2018), essa diversidade de formas encontrada na REF e REPHy atraía a atenção do leitor e tornava as orientações para a prática docente dinâmicas e de fácil entendimento. Em meio às disputas no campo editorial, esses dispositivos de leitura constituiam os grupos de intelectuais com autoridade para fornecer publicações de natureza didático-pedagógica, auxiliando o professor em sua atuação profissional. 
Nesse cenário, também era preciso criar um impresso com as características do BEF e que representasse a voz oficial do Governo, sem que um ou outro grupo fosse privilegiado. Era importante mediar as tensões que ocorriam na área, unificando-a. Fazia-se necessário um periódico que materializasse os marcos legais direcionados ao ensino da EF nos currículos escolares, consolidando-a. 0 BEF reconhecia o seu lugar de autoridade dentre aqueles dedicados à causa da EF, por isso, o uso de dispositivos visuais não era uma prioridade - o que contribuiria para a redução de seus custos, sobretudo por se tratar de um periódico gratuito. Além disso, a ausência de propagandas reforça o argumento da necessidade de se produzir um material com baixo valor de impressão, dada a impossibilidade de retorno financeiro com publicidade.

0 objetivo do editor não seria apresentar os mesmos dispositivos de leitura da REF e da REPHy, disputando o mercado editorial com elas. Por ser um instrumento oficial do Governo, cabia ao BEF veicular a unidade de doutrina pretendida para a área, por aqueles "[...] encarregados de fortalecer, física e moralmente, a sadia juventude que ha de conduzir o Brasil em seus verdadeiros destinos“ (LEITE, 1941a, s. p.).

Para o major Leite (1941a, s. p.), o objetivo do BEF era "[...] divulgar os trabalhos técnicos e as medidas administrativas que marcavam as atividades [...]” da DEF, de modo que houvesse melhor colaboração entre o Poder Público, os estabelecimentos de ensino e os professores. Cabia ao impresso estabelecer mediações entre os grupos de intelectuais, quer civis, quer militares, com o objetivo de conferir-lhe homogeneidade na orientação para a prática e formação de professores.

Assim, o impresso veiculava as realizações da DEF, tais como: normas federais e estaduais regulamentadoras da EF; prescrições para a atuação dos inspetores; condições para a realização das aulas de EF; e critérios para a realização dos grupamentos homogêneos. Ao se comprometer a alcançar leitores de "[...] lugares mais afastados da capital, [tornando] os interessados pelos assuntos de sua superintendência sempre informados do que vai se realizando" (LEITE, 1941b, p. 5), o editor divulgava as ações do Governo em prol da EF, mas, sobretudo, buscava consolidar um veículo de comunicação que pudesse unificá-la sob a propaganda do Estado Novo.

Para tanto, a publicação do BEF também estava associada ao Plano geral de propaganda da $\mathrm{EF}$, promovido pela $\mathrm{DEF}$, cujo objetivo era divulgar a causa da $\mathrm{EF}$, sob duas ações: pela circulação de conteúdo nos meios de comunicação, como o cinema e impressos; e pela promoção de concursos e produção de cartazes. Tais iniciativas se inseriam em um cenário político mais macro, caracterizado pela criação de órgãos responsáveis por difundir os discursos oficiais da Era Vargas.

De acordo com Luca (2011), a institucionalização do Departamento de Imprensa e Propaganda (DIP) pelo Governo tinha a finalidade de controlar os veículos de comunicação, editar diferentes suportes materiais (folhetos, livros, cartazes e periódicos) e elaborar concursos de monografias, que serviam como porta-vozes daquele projeto governamental. Mesmo que não identifiquemos a chancela do DIP ao BEF, a vinculação do impresso ao Governo permite-nos associá-lo aos mesmos princípios encontrados nos periódicos analisados por Luca (2011), especialmente pela necessidade de "alarde" aos avanços do regime de Vargas, no campo da Educação. 
A análise desse impresso também nos permitiu captar suas aproximações com a RBEF, especificamente em seu corpo editorial. 0 major João Barbosa Leite atuou como o primeiro diretor do BEF e da RBEF; e Inezil Penna Marinho, que já atuava com o major no âmbito do DEF (foi o chefe da Seção Técnico-Pedagógica), também assumiu a direção da RBEF, em 1946.

Como especificidade, vimos que a RBEF era originária de uma empresa comercial, com experiência na edição de livros e jornais, a Editora A Noite. 0 periódico fazia uso de dispositivos de leitura, como capas ilustradas e coloridas, publicidade (medicamentos, escritórios de advocacia, serviços bancários, moda e literatura) e acontecimentos sociais (nascimentos, casamentos e viagens de parentes de pessoas ligadas à DEF e à EF brasileira). Desse modo, oferecia uma variedade de informações aos seus leitores, a fim de diversificar o seu públicoalvo, além de fidelizar aquele oriundo da EF. A Figura 5 traz o seu primeiro editorial:

Figura 5 - Editorial da RBEF

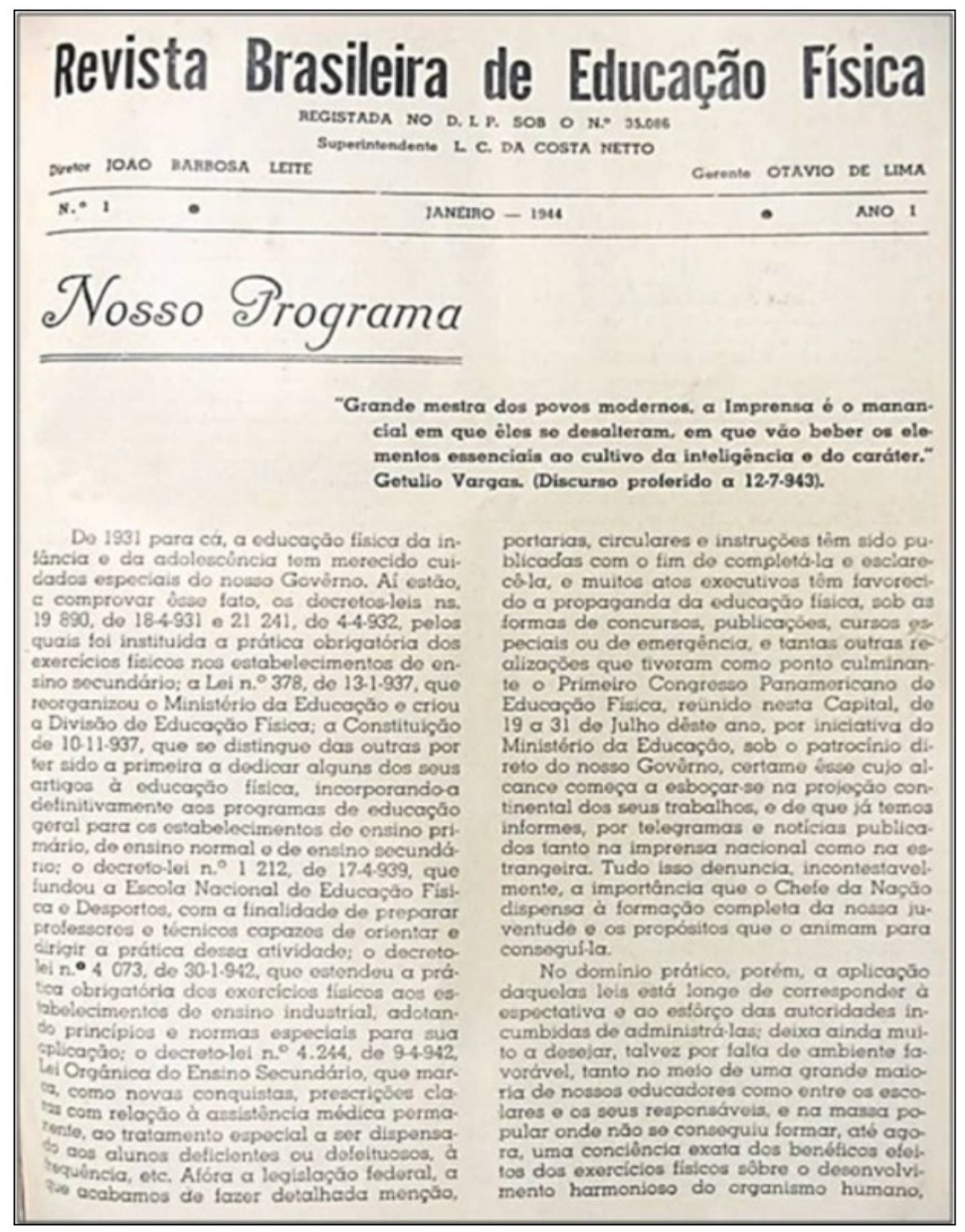

Fonte: Leite (1941a). 
0 título do editorial, com fonte em itálico e diferente do padrão utilizado em seu expediente e no corpo textual, remetia o leitor a uma grafia manual, em uma estratégia que conferia pessoalidade à matéria. Além disso, ele oferecia destaque aos propósitos da RBEF, mostrando para os professores os conteúdos que encontrariam em suas páginas:

[...] noticiário dos órgãos federais, estaduais e municipais, das escolas de EF, um editorial, [texto] clássico estrangeiro ou nacional, autor moderno, [...] e de [filosofia, pedagogia, biologia e esportes]. (LEITE, 1944, p. 3).

0 editor também ofereceu um panorama do desenvolvimento da EF no país. Eram evidentes, para ele, as iniciativas das legislações federais, as publicações de portarias e de instruções, que "complementariam" aquelas leis. Ao referir-se às suas próprias deliberações no âmbito da DEF, o major Leite $(1944$, p. 1) afirmava que "[...] muitos atos executivos [tinham] favorecido a propaganda da EF, sob as formas de concursos e publicações [...]”.

0 editor demonstrava certa insatisfação com o desenvolvimento da EF, pois, em sua opinião, no "domínio da prática", pouco era feito para corresponder às expectativas das autoridades que defendiam a causa da EF (LEITE, 1944). Assim, a responsabilidade das possíveis "ausências" percebidas no campo de atuação profissional eram atribuídas aos professores e às instituições de ensino, cabendo-lhes maior conscientização sobre o seu papel em prol do avanço da EF no país.

Para "auxiliar" nesse processo, Leite (1944) ressaltou o trabalho "imprescindível" da imprensa para orientação dos docentes, referenciando-se, no início de seu editorial, ao discurso de Vargas sobre a importância dos veículos de comunicação para cultivar a “inteligência” e o "caráter" dos leitores. Parece-nos contraditória a apropriação do texto assinado por Vargas, em um momento no qual foi criado um departamento para controlar a imprensa e "[...] difundir a imagem do país" (LUCA, 2011, p. 276). No entanto, não podemos desconsiderar que o uso da citação do Presidente se constituía em um dispositivo de leitura, a fim de convencer o professorado sobre a relevância da RBEF no mercado editorial, visto que se pautava em discursos oficiais.

A estratégia de Leite (1944, p. 2) em reconhecer na RBEF o meio mais seguro “[...] de divulgação de ideias, de alcance mais geral e de efeitos mais duradouros”, destacava a RBEF como um periódico que auxiliaria os professores a sistematizarem a sua prática, suprindo as lacunas de outras revistas, sobretudo porque elas não conseguiram manter as suas atividades. 0 editor se referia à paralisação da REF (em 1943, em decorrência da participação do Exército na Segunda Guerra Mundial) e às dificuldades financeiras enfrentadas pela REPHy, conforme anunciado em editorial (DOZE ANOS, 1944).

Leite (1944) não desconsiderou as contribuições desses impressos no processo de escolarização da EF, mas, em um cenário no qual a publicação de ambos estaria comprometida, a RBEF foi lançada como o periódico que consolidaria a formação e atuação profissional em EF. 0 editor afirmou: “[...] o aparecimento de várias revistas técnicas, nos últimos 15 anos, [foi] acertado, [pois tinham o] intuito de debater os assuntos desse ramo de atuação, [...] [mas, precisamos] de novas e mais seguras investidas” (LEITE, 1944, p. 2).

Como diretor da DEF, o major Leite compreendia as necessidades da área, afırmando que a RBEF foi elaborada em decorrência da procura "insistente" de professores e técnicos 
que, mesmo cientes dos problemas encontrados pelos outros periódicos, pediam por novas revistas técnicas especializadas (LEITE, 1944). Para tornar a RBEF uma referência entre os leitores, o editor estrategicamente reforçava a colaboração do impresso com o Governo e com os educadores, bem como se comprometia a difundir os "[...] conhecimentos acumulados sôbre a matéria de sua especialidade" (LEITE, 1944, p. 2).

A análise das fontes permite-nos inferir que a elaboração de um novo periódico para EF, bem como a circulação de outras projeções para o seu ensino, não significavam o silenciamento dos saberes já produzidos pela área. Ainda que se pretendesse assumir o lugar de impressos que, naquele momento, não apresentavam estabilidade, houve o reconhecimento do editor em relação aos estudos outrora produzidos e que também contribuíram para a inserção da EF nos currículos escolares. A estratégia editorial para estabelecer a RBEF entre os professores não seria a ruptura, mas sim a continuidade e ampliação das teorias e das orientações didático-pedagógicas já conhecidas por eles.

Por sua vez, os AENEFDs foram publicados entre 1945 e 1966, com interrupção em seu ciclo de vida nos anos de 1950 a 1952. 0 impresso foi chancelado pela Escola Nacional de EF e Desportos (Enefd), instituição pertencente à Universidade do Brasil (UB). ${ }^{10}$ A Figura 6 apresenta o seu primeiro editorial:

Figura 6 - Editorial dos AENEFDs

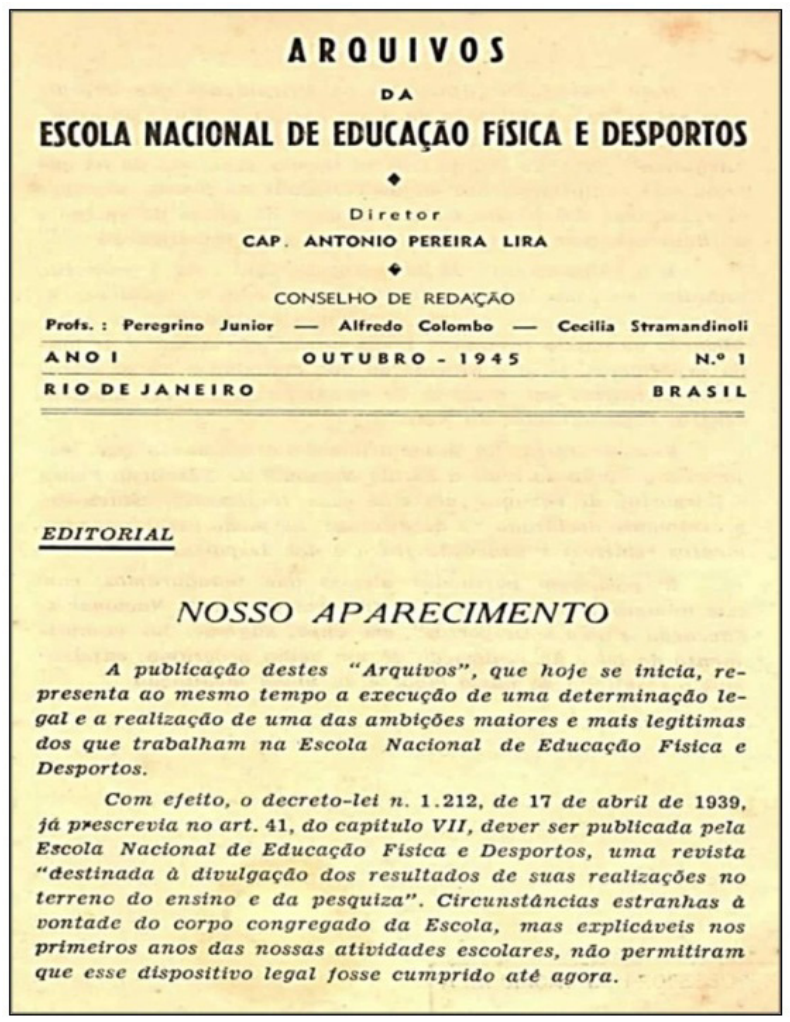

Fonte: Lira (1945).

10 - Instituição criada em 5 de julho de 1937, período em que Gustavo Capanema era o Ministro da Educação e Saúde. 
0 uso da fonte em itálico, em todo o Editorial, diferia-se daquela utilizada no Expediente do periódico. 0 seu título, em caixa-alta e sublinhado, também conferia visibilidade ao teor ali abordado.

No texto, o editor Cap. Antônio Pereira Lira explicou que os AENEFDs materializavam o que determinava o art. 41 do Decreto-Lei no 1.212, de 17 de abril de 1939, sobre a criação da Enefd, no âmbito da UB. No documento, definiu-se a necessidade de uma publicação periódica que divulgasse os resultados de ensino e de pesquisa realizados na UB. Para Lira (1945, s. p.), o objetivo da revista era “[...] divulgar os resultados dos trabalhos [da Enefd], fruto de apurado estudo e de longa experiência, para a difusão de bôa doutrina e da sã orientação científica em matéria de EF”. Mesmo após a paralisação de suas atividades, o impresso permaneceu com esse perfil, “[...] [divulgando] os frutos de nossa experiência e do nosso trabalho, [...] [seja] no plano teórico da doutrina [seja] no plano pragmático da aplicação e da prática" (EDITORIAL, 1953, p. 6).

Os AENEFDs assumiram como especificidade publicar artigos com orientações para a prática dos professores e fundamentados em iniciativas de pesquisas. Esse fazer científico, até então não estruturado em outros periódicos, apresentava os resultados dos trabalhos desenvolvidos pelos docentes da Enefd, obtidos "[...] no plano da ciência, da pedagogia, da aplicação prática dos conhecimentos ensinados” (EDITORIAL, 1954, p. 5).

Os AENEFDs exerceram papel fundamental na transição entre os periódicos de ensino e de técnicas para aqueles chancelados por instituições universitárias e sociedades científicas. A sua publicação significou mudanças gradativas no que se refere ao projeto editorial da imprensa periódica de ensino e técnicas, pois, inicialmente ela oferecia orientações didático-pedagógicas para o ensino da EF, contribuindo com a sua inserção e consolidação nos currículos escolares. Ao final do seu ciclo de vida, ela apresentou outras características, especificamente nos AENEFDs, fornecendo as bases para os periódicos de natureza científica.

\section{Considerações finais}

Este artigo analisou as estratégias utilizadas pelos editores para constituir a imprensa periódica de ensino e de técnicas como meio de divulgação e convencimento do professorado, no que se refere à incorporação da educação física (EF) nos currículos escolares. Os resultados sinalizam que a Revistas de Educação Física (REF) e a Revista Educação Physica (REPHy) foram elaboradas em um cenário de luta pela inserção da EF nas escolas, no qual era necessário oferecer aos professores dispositivos de uso didático-pedagógico que os auxiliasse a ministrar as suas aulas. À época, pretendia-se a homogeneização de suas práticas, em um cenário de disputas e negociações entre os grupos de intelectuais que orientariam o ensino da EF.

Já o Boletim de Educação Física (BEF) e a Revista Brasileira de Educação Física (RBEF) foram criados em um contexto de consolidação de um projeto governamental, que visava à centralização das políticas educacionais. Nesse processo, os editores focalizavam a unificação da EF em território nacional, tendo como base o reconhecimento da trajetória dos periódicos anteriores a eles. Por sua vez, os Arquivos da Escola Nacional de Educação Física (AENEFDs) contribuíram para a consolidação da formação de futuros professores 
de EF, sobretudo por meio da pesquisa, caracterizando-se como o impresso que lançou as bases para o periodismo científico na EF.

A circulação de militares como editores em diferentes impressos fez com que o projeto educacional pensado pelo Exército oferecesse os alicerces para o perfil editorial da REF, do BEF, da RBEF e dos AENEFDs, o que não significa consenso teórico e publicações baseadas apenas no método francês. Por outro lado, a REPHy reconhecia o lugar de permanência da REF, operando práticas de negociação e complementaridade em relação aos militares. 0 mesmo ocorria com a REF, ao buscar o "diálogo" com intelectuais civis, para que fossem elaboradas as bases científicas para a EF.

A análise das fontes de pesquisa apresentadas nesse artigo evidenciou que os grupos de articulistas à frente dos editoriais criaram identidades para os impressos analisados, com base nos lugares institucionais ocupados por eles. Com suas estratégias, buscavam escolarizar a EF e significar simbolicamente um estatuto e uma posição para si, constituindo-se como autoridades.

\section{Referências}

BASTOS, Maria Helena Camara. Apêndice: A imprensa periódica educacional no Brasil (1808-1944). In: CATANI, Denice Barbara; BASTOS, Maria Helena Camara (org.). Educação em Revista: a imprensa periódica e a história da educação. São Paulo: Escrituras, 1997. p. 173-187.

BRASIL. Decreto n 19.890. Rio de Janeiro, 18 de abril de 1931. Disponível em: https://www2.camara. leg.br/legin/fed/dec ret/1930-1939/decreto-19890-18-abril1931-504631-publicacaooriginal-141245pe.html. Acesso em: 28 out. 2020.

CAPA. Boletim de Educação Física, Rio de Janeiro, ano 1, n. 1, s. p., jun. 1941.

CARVALHO, Marta Maria Chagas de. A caixa de utensílios e a biblioteca: pedagogia e práticas de leitura. In: VIDAL, Diana Gonçalves; HILSDORF, Maria Lucia Spedo (org.). Brasil 500 anos: tópicas em história da educação. São Paulo: Edusp, 2001. p. 137-167.

CASSANI, Juliana Martins. Da imprensa periódica de ensino e de técnicas aos livros didáticos da educação física: trajetórias de prescrições pedagógicas (1932-1960). 2018. Tese (Doutorado em Educação Física) - Universidade Federal do Espírito Santo, Vitória, 2018.

CATANI, Denice Barbara. Perspectivas de investigação e fontes para a história da educação brasileira: a imprensa periódica educacional. In: CATANI, Denice Barbara (org.). Ensaios sobre a produção e circulação dos saberes pedagógicos. São Paulo: Dedalus, 1994. p. 58-76.

CATANI, Denice Barbara; SOUSA, Cynthia Pereira de. 0 catálogo da imprensa periódica educacional paulista (1890-1996): um instrumento de pesquisa. In: CATANI, Denice Barbara (org.). Imprensa periódica educacional paulista (1890-1996): catálogo. São Paulo: Plêiade, 1999. p. 9-30.

CAVALCANTI, Newton. Unidade de doutrina. Revista de Educação Física, Rio de Janeiro, v. 1, n. 2, [s. p.], jun. 1932. 
CERTEAU, Michel de. A invenção do cotidiano: 1. Artes de fazer. 15. ed. Petrópolis: Vozes, 2002.

CHARTIER, Roger. À beira da falésia: a história cultural entre certezas e inquietudes. Porto Alegre: UFRGS, 2002. CHARTIER, Roger. A história cultural: entre práticas e representações. Lisboa: Difel, 1990.

CHARTIER, Roger. A mão do autor e a mente do editor. São Paulo: Unesp, 2014.

CHATEAUBRIAND, Assis. Dinâmica corporal. Revista de Educação Física, Rio de Janeiro, v. 3, n. 18, p. 1, dez. 1934.

DOZE anos de luta e perseverança. Educação Física, Rio de Janeiro, n. 79/80, p. 5, maio/jun. 1944.

EDITORIAL. Educação Physica, Rio de Janeiro, n. 4, p. 11, mar. 1934.

EDITORIAL. Educação Physica, Rio de Janeiro, n. 5, p. 11, abr. 1936.

EDITORIAL. Educação Physica, Rio de Janeiro, n. 15, p. 9, fev. 1938.

EDITORIAL. Arquivos da Escola Nacional de Educação Física e Desportos, Rio de Janeiro, v. 6, n. 6, p. 5-6, jan. 1953.

EDITORIAL. Arquivos da Escola Nacional de Educação Física e Desportos, Rio de Janeiro, v. 7, n. 7, p. 5-6, jan. 1954.

FARIA, Maria Isabel; PERICÃO, Maria da Graça. Dicionário do livro: da escrita ao livro eletrônico. São Paulo: Edusp, 2008.

FERREIRA NETO, Amarílio. A pedagogia no Exército e na escola: a educação física (1920-1945). Motrivivência, Florianópolis, v. 9, n. 13, p. 35-62, nov. 1999.

FERREIRA NETO, Amarílio. Publicações periódicas científicas em educação física e esporte de instituições universitárias. In: DACOSTA, Lamartine Pereira (org.). Atlas do esporte no Brasil. Rio de Janeiro: Shape, 2005b. p. 778-779.

FERREIRA NETO, Amarílio. Publicações periódicas de ensino, de técnicas e de magazines em educação física e esporte. In: DACOSTA, Lamartine Pereira (org.). Atlas do esporte no Brasil. Rio de Janeiro: Shape, 2005a. p. 776-777.

FERREIRA NETO, Amarílio et al. Catálogo de periódicos de educação física e esportes (1930- 2000). Vitória: Proteoria, 2002.

GINZBURG, Carlo. Mitos, emblemas e sinais: morfologia e história. São Paulo: Companhia das Letras, 1989.

LEITE, João Barbosa. [Sem título]. Boletim de Educação Física, Rio de Janeiro, v. 1, n. 1, [s. p.], jun. 1941a. 
LEITE, João Barbosa. [Sem título]. Boletim de Educação Física, Rio de Janeiro, v. 1, n. 3, p. 5, dez. 1941 b. LEITE, João Barbosa. Nosso programa. Revista Brasileira de Educação Física, Rio de Janeiro, v. 1, n. 1, [s. p.], jan. 1944.

LIRA, Antônio Pereira. Editorial. Arquivos da Escola Nacional de Educação Física e Desportos, Rio de Janeiro, v. 1, n. 1, [s. p.], out. 1945.

LUCA, Tania Regina de. A produção do Departamento de Imprensa e Propaganda em acervos norte americanos: estudo de caso. Revista Brasileira de História, São Paulo, v. 31, n. 61, p. 271-296, jun. 2011.

MOLINA, Antônio de Mendonça. Importância da educação física para um povo: o método adotado. Revista de Educação Física, Rio de Janeiro, v. 1, n. 3, [s. p.], jul. 1932.

PINHEIRO, João Ribeiro. Militarismo e educação física. Revista de Educação Física, Rio de Janeiro, v. 1, n. 1, [s. p.], maio 1932a.

PINHEIRO, João Ribeiro. 0 exercito e $05^{\circ}$ congresso de educação. Revista de Educação Física, Rio de Janeiro, v. 1, n. 2, [s. p.], jun. 1932b.

RETZ, Renato Pereira Coimbra et al. 0 ensino por imagens na imprensa periódica da educação física (1932- 1960). Revista Brasileira de História da Educação, Campinas, v. 19, p. e058, 2019.

REVISTA TECHNICA que visa apoiar a causa da educação physica. Educação Physica, Rio de Janeiro, s. p, 1932.

VIDAL, Diana Gonçalves. 80 anos do Manifesto dos Pioneiros da Educação Nova: questões para debate. Educação e Pesquisa, São Paulo, v. 39, n. 3, p. 577-588, jul./set. 2013.

XAVIER, Libânia Nacif. Para além do campo educacional: um estudo sobre o que ensinar o Manifesto dos Pioneiros da Educação Nova (1932). Bragança Paulista: Edusf, 2002.

Recebido em: 13.06.2019

Aprovado em: 10.09.2019

Juliana Martins Cassani é pós-doutora, doutora e mestre em educação física pela pela Universidade Federal do Espírito Santo (UFES). Pesquisadora do Instituto de Pesquisa em Educação e Educação Física (Proteoria/UFES).

Amarílio Ferreira Neto é doutor em educação pela Universidade Metodista de Piracicaba (UNIMEP). É professor do Programa de Pós-Graduação em Educação Física da Universidade Federal do Espírito Santo (UFES). Pesquisador do Instituto de Pesquisa em Educação e Educação Física (Proteoria/UFES). 
Wagner dos Santos é doutor em educação pela Universidade Federal do Espírito Santo (UFES). É professor do Programa de Pós-Graduação em Educação e Educação Física da UFES (Mestrado e Doutorado). Líder do Instituto de Pesquisa em Educação e Educação Física (Proteoria/UFES). É bolsista de produtividade em pesquisa do CNPq - Nível 2. 